\title{
Characteristics of Post-traumatic-spondyloarthritis: A Cross-sectional Study From a Single Tertiary Hospital
}

\author{
Hong Ki Min, M.D. ${ }^{1}$, Hyonjoung Cho, M.D. ${ }^{2}$, Sung-Hwan Park, M.D., Ph.D. ${ }^{3}$ \\ ${ }^{1}$ Division of Rheumatology, Department of Internal Medicine, Konkuk University Medical Center, Seoul, ${ }^{2}$ Division of Rheumatology, Department \\ of Internal Medicine, Armed Forces Capital Hospital, Armed Forces Medical Command, Seongnam, ${ }^{3}$ Division of Rheumatology, Department of \\ Internal Medicine, School of Medicine, The Catholic University of Korea, Seoul, Korea
}

\begin{abstract}
Objective. Trauma has been proposed as a triggering factor of psoriatic arthritis (PsA), and the deep Koebner phenomenon was the suggested underlying mechanism. The relationship between spondyloarthritis (SpA) and trauma was only observed in PsA. This study investigated cases of SpA other than PsA that occurred after physical trauma and analyzed their clinical, laboratory, and radiologic features. Methods. We retrospectively reviewed the medical records of 213 patients who visited our hospital due to a suspicion of SpA and grouped them into post-traumatic-SpA (PT-SpA, n =12) and non-post-traumatic-SpA (non-PT-SpA, $n=201$ ). Baseline characteristics were compared between the two groups by cross-sectional manner. Results. Peripheral $S p A$ was more common in PT-SpA than in non-PT-SpA. Active inflammation on sacroiliac joint (SIJ) magnetic resonance imaging (MRI) was more common in non-PT-SpA (83.5\% vs. 54.5\%, p=0.046). The modified Stoke Ankylosing Spondylitis Spine Score (mSASSS) was significantly higher in the non-PT-SpA group (2.0 vs. 0.0, $\mathrm{p}=0.007$ ). Symptom duration from the first SpA symptom to diagnosis tends to be longer in the non-PT-SpA group ( 2.0 vs. 0.5 years, $p=0.079$ ). Conclusion. PT-SpA patients more frequently showed peripheral SpA, a less active inflammatory lesion on SIJ MRI, and a lower mSASSS score. Further studies are needed to clarify whether physical trauma has a direct/indirect role in the pathogenesis of SpA or merely confers an opportunity to recognize SpA symptoms. (J Rheum Dis 2021;28:25-30)
\end{abstract}

Key Words. Post-traumatic, Peripheral spondyloarthritis, Spondyloarthritis, Triggering factor

\section{INTRODUCTION}

Spondyloarthritis ( $\mathrm{SpA})$ is characterized by a young-age onset, inflammatory back pain, and an association with human leukocyte antigen (HLA)-B27. SpA can be divided into two forms: axial and peripheral SpA according to the dominant symptom, axial joint arthritis or peripheral arthritis/dactylitis/enthesitis [1]. SpA can also subclassified to ankylosing spondylitis (AS), psoriatic arthritis (PsA), inflammatory bowel disease associated SpA, reactive arthritis, and undifferentiated SpA [1]. The pathogenesis of SpA is not fully evaluated yet, but several factors are suggested as the underlying pathologic mechanisms. A genetic background such as HLA-B27 showed an ob- vious relationship with SpA pathogenesis, and recently dysbiosis, disruption of normal flora, emerged as a novel environmental triggering factor of SpA [2]. Another environmental factor, biomechanical stress, has been suggested as one of the triggering factors of SpA; most of the evidence was based on clinical data of PsA and the mice model of SpA [3-5].

Environmental factors related to the pathogenesis of SpA are not well known. Smoking is a known aggravating factor, but the role of smoking on the onset of SpA is not clear [6]. Dysbiosis has been suggested as another environmental pathologic factor. Several studies showed altered microbiota in SpA by comparing fecal microbiota with healthy controls $[7,8]$. Lifting heavy weights $(>100$

Received : August 9, 2020, Revised : September 8, 2020, Accepted : September 23, 2020

Corresponding to : Sung-Hwan Park (iD http://orcid.org/0000-0003-1711-2060

Division of Rheumatology, Department of Internal Medicine, Seoul St. Mary's Hospital, College of Medicine, The Catholic University of Korea, 222 Banpo-daero, Seocho-gu, Seoul 06591, Korea. E-mail : rapark@catholic.ac.kr 
pounds/hr), bone or joint trauma history, and physical trauma requiring medical care increased the risk of PsA occurrence $[5,9,10]$. Furthermore, AS patients with previous job requiring dynamic flexibility had higher radiographic damage [11]. In addition, mice models of SpA displayed physical loading aggravated enthesitis; and abnormal new bone formation was promoted in entheses when biomechanical stress was applied [4]. The underlying mechanism relating trauma and PsA was hypothesized as the "deep Koebner" response [12]. However, clinical data concerning SpA occurring after physical trauma, other than PsA, has not been published. Finally, previous studies only included PsA patients from Western countries.

To establish the characteristics of post-traumatic-SpA (PT-SpA) other than PsA, in an Asian population, we investigated the clinical, laboratory, and radiologic findings of PT-SpA in Korea. We also compared the clinical, laboratory, and radiologic findings in PT-SpA and nonPT-SpA.

\section{MATERIALS AND METHODS}

\section{Patients}

We retrospectively reviewed the medical records of patients who visited a tertiary army hospital for suspicion of SpA between January 2016 and April 2017. Most of the patients were referred from other twelve army hospital because the Armed Forces Capital hospital only has rheumatology clinic. The inclusion criteria were as follows: (1) fulfilment of the Assessment of SpondyloArthritis (ASAS) classification criteria for axial or peripheral SpA $[1,13]$, (2) age 18 to 40 years, and (3) initial diagnosis in our hospital. The presence of peripheral arthritis, enthesitis, and dactylitis was confirmed by physical examination and recorded in the medical records. Peripheral SpA was diagnosed if the dominant symptoms were peripheral, such as peripheral arthritis, enthesitis, or dactylitis [13]. PT-SpA was defined when SpA symptoms first occurred after definite physical trauma such as fracture, contusion, or excessive weight bearing exercise which required medical care [10]. The exclusion criteria of the PT-SpA group were as follows: (1) having a prior history of inflammatory arthritis, (2) a history of arthralgia or back pain before the event, and (3) remote trauma history further than 6 months from initial SpA symptom. Furthermore, to distinguish SpA symptom from trauma related symptoms, we only included PT-SpA patients when the arthralgia maintained at least 3 months after the initial trauma happened, and other causes for arthralgia were excluded. Initially, a total 291 patients were diagnosed as axial or peripheral SpA based on the ASAS classification criteria $[1,13]$, and 78 of them were excluded from the analysis because of incomplete laboratory or clinical data. Finally, 213 patients with axial or peripheral SpA were included in the analysis, and baseline characteristics were analyzed as cross-sectional manner. Acquisition of informed consent was omitted because this study was based on retrospective chart review. All experiments were conducted in accordance with the Declaration of Helsinki. This study was approved by the Institutional Review Board of our hospital (AFMC-17093-IRB-17-089).

\section{Radiologic findings}

Initial radiologic data included magnetic resonance imaging (MRI) of the sacroiliac joint (SIJ) and plain radiography of the SIJ, cervical spine, and lumbar spine. Active sacroiliitis (bone marrow edema in SIJ) was defined as high signal intensity on T2-weighted sequences sensitive to water [14]. The modified Stoke Ankylosing Spondylitis Spine Score (mSASSS) was measured using cervical and lumbar spine radiography and the existence of syndesmophytes was clarified [15]. The grade of sacroiliitis was scored according to the modified New York criteria [16].

\section{Demographic, clinical, and laboratory profiles}

Patients' clinical data and laboratory findings, including HLA-B27, were collected at the time of the first visit to our hospital. Elevation of C-reactive protein (CRP) and erythrocyte sedimentation rate (ESR) were defined as over $0.3 \mathrm{mg} / \mathrm{dL}$ and $20 \mathrm{~mm} / \mathrm{hr}$, respectively. Items constituting ASAS classification criteria for axial or peripheral SpA were recorded. Groups were divided based on the presence or absence of a definite physical trauma before onset of SpA symptoms.

\section{Statistical analysis}

Normal distribution of continuous variables was assessed by the Kolmogorov-Smirnov test. Based on normal distribution test, continuous variables were compared by either the Student's t-test or Mann-Whitney U-test, and presented as mean \pm standard deviation or median with interquartile range. Categorical variables were compared by using the chi-squared test or Fisher's exact test. Values of $p<0.05$ were considered statistically significant. All 


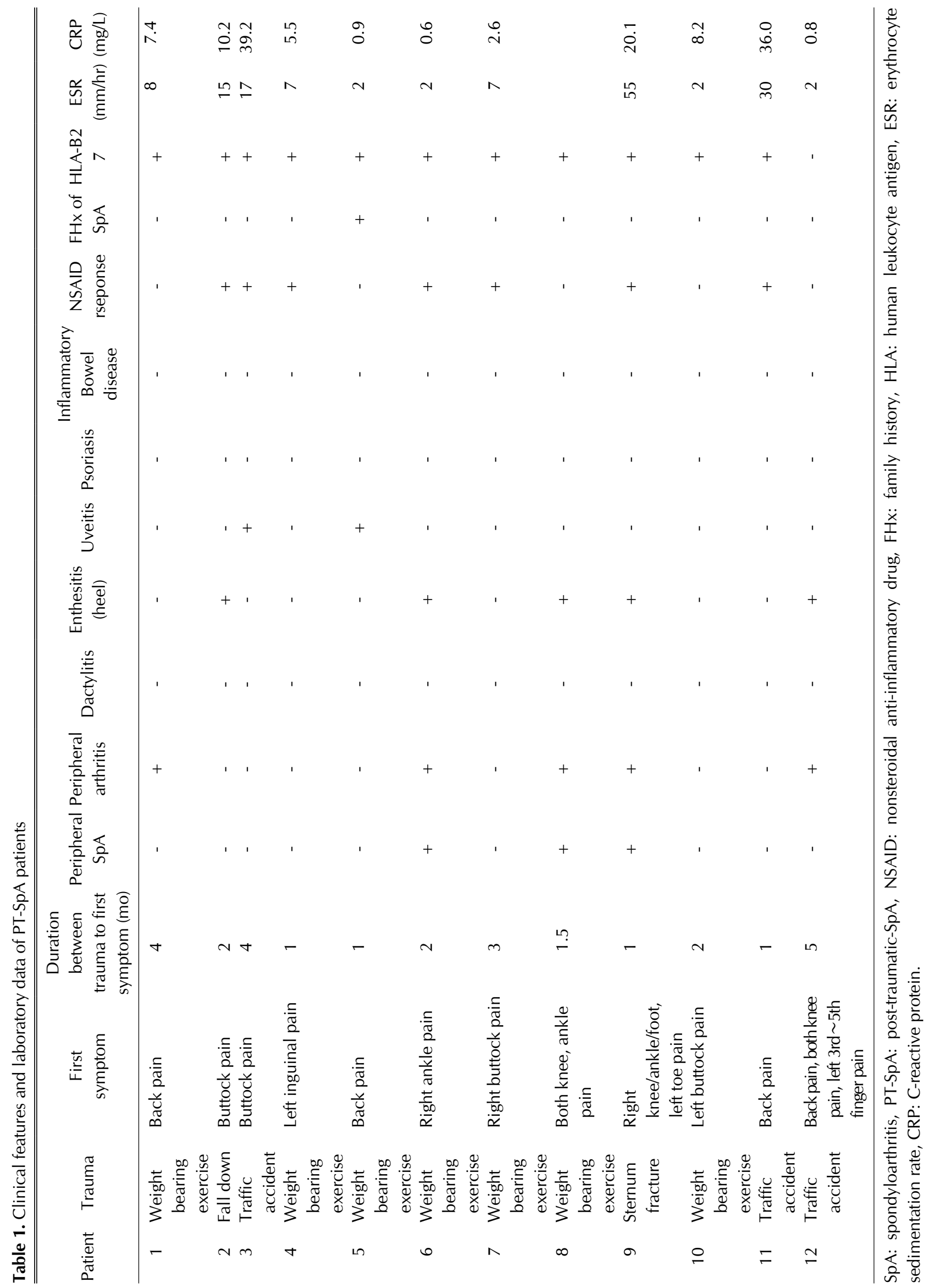


tests were performed with the software $\mathrm{R}$ ( $\mathrm{R}$ for Windows 3.3.2; The $\mathrm{R}$ Foundation for Statistical Computing, Vienna, Austria).

\section{RESULTS}

\section{Baseline clinical characteristics, laboratory profiles, and clinical features of patients with PT-SpA}

We found 12 patients with PT-SpA among 213 SpA patients. All PT-SpA patients were male. The clinical characteristics, items constituting the ASAS classification criteria for SpA, and laboratory findings of the 12 PT-SpA patients are presented in Table 1. Eleven patients (91.7\%) were positive for HLA-B27, and the CRP level was elevated in seven patients (63.6\%).

\section{Comparison between patients with PT-SpA and non-PT-SpA}

Table 2 shows the comparison of clinical parameters and items constituting the ASAS classification criteria for SpA between PT-SpA and non-PT-SpA groups. The prevalence of peripheral SpA was significantly higher in the PT-SpA than in the non-PT-SpA $(25.0 \%$ vs. $1.5 \%, \mathrm{p}<0.001)$. Symptom duration from the first SpA symptom to diagnosis tends to be shorter in PT-SpA. No significant difference regarding the items of ASAS classification criteria was noted between the two groups.

Laboratory and radiologic findings were compared and

Table 2. Comparison of clinical and SpA features between PT-SpA and non-PT-SpA

\begin{tabular}{lccc}
\hline \multicolumn{1}{c}{ Variable } & $\begin{array}{c}\text { Post-traumatic-SpA (PT-SpA) } \\
(\mathrm{n}=12)\end{array}$ & $\begin{array}{c}\text { Non-PT-SpA } \\
(\mathrm{n}=201)\end{array}$ & $\mathrm{p}$-value \\
\hline Age & $21.0(20.0 \sim 25.0)$ & $21.0(20.0 \sim 23.0)$ & 0.771 \\
Sex, male & $12(100.0)$ & $201(99.5)$ & 1.000 \\
Symptom duration (first SpA symptom to diagnosis, yr) & $0.5(0.25 \sim 3.0)$ & $2.0(0.5 \sim 4.0)$ & 0.079 \\
Peripheral SpA & $3(25.0)$ & $3(1.5)$ & $<0.001$ \\
Enthesitis (heel) & $5(41.7)$ & $49(24.4)$ & 0.319 \\
Uveitis & $2(16.7)$ & $38(18.9)$ & 1.000 \\
Psoriasis & 0 & $4(2.0)$ & 1.000 \\
Inflammatory bowel disease & 0 & 0 & 1.000 \\
CRP elevation & $7 / 11(63.6)$ & $112 / 199(56.3)$ & 0.868 \\
Alternating buttock pain & $7(58.3)$ & $110(54.7)$ & 1.000 \\
Good response to NSAID & $7(58.3)$ & $132(65.7)$ & 0.836 \\
Family history of SpA & $1(8.3)$ & $26(12.9)$ & 0.985 \\
Peripheral arthritis & $5(41.7)$ & $85(42.3)$ & 1.000 \\
Dactylitis & 0 & $3(1.5)$ & 1.000 \\
\hline
\end{tabular}

Values are presented as median (interquartile range) or number (\%). SpA: spondyloarthritis, CRP: C-reactive protein, NSAID: nonsteroidal anti-inflammatory drug.

Table 3. Comparison of laboratory and radiologic findings between PT-SpA and non-PT-SpA

\begin{tabular}{lccc}
\hline \hline \multicolumn{1}{c}{ Variable } & $\begin{array}{c}\text { Post-traumatic-SpA (PT-SpA) } \\
(\mathrm{n}=12)\end{array}$ & $\begin{array}{c}\text { Non-PT-SpA } \\
(\mathrm{n}=201)\end{array}$ & $p$-value \\
\hline HLA-B27 & $11 / 12(91.7)$ & $174 / 199(87.4)$ & 1.000 \\
ESR $(\mathrm{mm} / \mathrm{hr})$ & $7.0(2.0 \sim 16.0)$ & $7.0(2.0 \sim 18.0)$ & 0.890 \\
CRP $(\mathrm{mg} / \mathrm{L})$ & $0.7(0.2 \sim 1.5)$ & $0.3(0.1 \sim 1.5)$ & 0.549 \\
Sacroiliitis grade of right SIJ & $2.0(1.0 \sim 3.0)$ & $3.0(1.0 \sim 3.0)$ & 0.323 \\
Sacroiliitis grade of left SIJ & $2.0(1.0 \sim 3.0)$ & $2.0(1.0 \sim 3.0)$ & 0.565 \\
Active inflammation on SIJ MRI & $6 / 11(54.5)$ & $131 / 157(83.4)$ & 0.047 \\
mSASSS score & 0.0 & $2.0(1.0 \sim 16.0)$ & 0.007 \\
Syndesmophyte & $0 / 5$ & $17 / 135(12.6)$ & 0.881 \\
\hline
\end{tabular}

Values are presented as number (\%) or median (interquartile range). HLA: human leukocyte antigen, ESR: erythrocyte sedimentation rate, CRP: C-reactive protein, SIJ: sacroiliac joint, MRI: magnetic resonance imaging, mSASSS: modified Stoke Ankylosing Spondylitis Spine Score. 
summarized in Table 3. An active inflammatory lesion (bone marrow edema) on SIJ MRI was less frequent in the PT-SpA, and the mSASSS score was also lower in the PT-SpA than in the non-PT-SpA (54.5\% vs. $83.4 \%$, $\mathrm{p}=0.047,0$ vs. $2.0, \mathrm{p}=0.007$, respectively).

\section{DISCUSSION}

The present study aimed to clarify the features of PT-SpA patients other than PsA and to compare the characteristics of patients with PT-SpA and non-PT-SpA. PT-SpA showed a higher prevalence of peripheral SpA than non-PT-SpA. Other SpA characteristics were similar between the two groups. An active inflammatory lesion (bone marrow edema) of SIJ was more frequent and spinal structural damage (mSASSS) was more severe in the non-PT-SpA group. Only one patient (Patient No.2 of PT-SpA) complained of the site where he was injured as the site of the first SpA symptom whereas others complained of the first arthralgia in a distant joint. This supports the hypothesis that preceding physical trauma could provoke the symptoms of SpA not only by direct biomechanical stress but also by a systemic immune response such as "Deep Koebner" response [12].

Previous studies revealed an increased risk of PsA occurrence in patients with psoriasis $(\mathrm{PsO})$ who experienced physical trauma $[5,10]$. Another study showed lifting heavy loads had increased odds of PsA among PsO patients [9]. Recently, Tinazzi et al. [17] showed increased A1 pulley thickness in PsA patients compared with RA, $\mathrm{PsO}$, and healthy controls. The "Deep Koebner" phenomenon was suggested as an underlying mechanism that could explain how physical stress or trauma contributes to the occurrence of PsA in patients with underlying $\mathrm{PsO}$ $[12,17]$. Although the precise mechanism of the 'deep Koebner' response is not elucidated, it might also explain the role of biomechanical stress on the pathogenesis of SpA other than PsA. Previous studies seeking a relationship between physical trauma and the occurrence of PsA were conducted in Europe and North America. Racial differences exist between Caucasians and Asians patients with SpA in that Caucasians with SpA have a higher prevalence of psoriasis than Asian SpA patients [18-21]. Also, previous studies that revealed an association between physical trauma and SpA were limited by their inclusion of only PsA in the analysis $[5,9,10,17]$. This study was the first performed in Asia and the first to include SpA other than PsA.
Entheses are the known target of musculoskeletal inflammation in the pathogenesis of SpA including PsA. In SpA patients, low-level mechanical stress on entheses might induce enthesitis. Activation of localized $\gamma \delta \mathrm{T}$ cells and type 3 innate lymphoid cells of entheses may induce an immune response [22]. Mice models of SpA showed unloading of the hind limb attenuated enthesitis, peripheral arthritis, and abnormal new bone formation compared with weight bearing controls [4]. In this study, PT-SpA patients showed higher frequency of peripheral SpA than non-PT-SpA. Although the underlying mechanisms of physical trauma in SpA occurrence have not been fully elucidated, based on this research, future studies might reveal the role of physical trauma in SpA pathogenesis, especially enthesitis and peripheral arthritis.

The present study has several limitations. First, the sample size of enrolled PT-SpA patients was small. However, this was the first study to enroll PT-SpA other than PsA, and in an Asian population. Second, all the PT-SpA patients included in the present study were young male because Korea is running a conscription system, not a recruitment system. Therefore, our results may not apply to PT-SpA in female and elderly patients. Third, this study was cross-sectional and included only baseline data; thus, follow-up data were unavailable. The clinical course of PT-SpA was not demonstrated. Forth, trauma was checked according to interview and electric medical record, the intensity of trauma was not measured. Fifth, complete exclusion of physical trauma history in non-PT-SpA group was impossible, because the present study was based on medical records review. Finally, experiments to discover the mechanism whereby physical trauma effects SpA pathogenesis are not included. Therefore, whether physical trauma is a triggering factor in SpA pathogenesis or solely an opportunity to recognize SpA symptoms is unclear.

\section{CONCLUSION}

Physical trauma might play a direct role in the pathogenesis of SpA or might present an opportunity to recognize SpA symptoms in previously undiagnosed SpA patients. We evaluated characteristics of 12 cases of PT-SpA in SpA patients other than PsA in Korea for the first time. These PT-SpA patients had a higher prevalence of peripheral SpA, and active inflammation on MRI was less common than in patients with non-PT-SpA. The mSASSS score was lower in patients with PT-SpA. 
Further studies are required to clarify whether physical trauma has a direct pathologic role on SpA occurrence.

\section{ACKNOWLEDGMENTS}

We appreciate the statistical assistance of the medical research collaboration center at Konkuk University Medical Center.

\section{CONFLICT OF INTEREST}

No potential conflict of interest relevant to this article was reported.

\section{AUTHOR CONTRIBUTIONS}

H.K.M. made conceptualization of the study, data curation, interpretation of the data, and writing the original manuscript. H.J.C. involved in data collection and interpretation of the data. S.H.P. involved in conceptualization, revision of the manuscript.

\section{REFERENCES}

1. Sieper J, Rudwaleit M, Baraliakos X, Brandt J, Braun J, Burgos-Vargas R, et al. The Assessment of SpondyloArthritis international Society (ASAS) handbook: a guide to assess spondyloarthritis. Ann Rheum Dis 2009;68 Suppl 2:ii1-44.

2. Ranganathan V, Gracey E, Brown MA, Inman RD, Haroon N. Pathogenesis of ankylosing spondylitis - recent advances and future directions. Nat Rev Rheumatol 2017;13:359-67.

3. Van Mechelen M, Lories RJ. Microtrauma: no longer to be ignored in spondyloarthritis? Curr Opin Rheumatol 2016; 28:176-80.

4. Jacques P, Lambrecht S, Verheugen E, Pauwels E, Kollias G, Armaka M, et al. Proof of concept: enthesitis and new bone formation in spondyloarthritis are driven by mechanical strain and stromal cells. Ann Rheum Dis 2014;73:437-45.

5. Thorarensen SM, Lu N, Ogdie A, Gelfand JM, Choi HK, Love TJ. Physical trauma recorded in primary care is associated with the onset of psoriatic arthritis among patients with psoriasis. Ann Rheum Dis 2017;76:521-5.

6. Poddubnyy D, Haibel H, Listing J, Märker-Hermann E, Zeidler $\mathrm{H}$, Braun J, et al. Baseline radiographic damage, elevated acute-phase reactant levels, and cigarette smoking status predict spinal radiographic progression in early axial spondylarthritis. Arthritis Rheum 2012;64:1388-98.

7. Stoll ML. Gut microbes, immunity, and spondyloarthritis. Clin Immunol 2015;159:134-42.

8. Breban M, Tap J, Leboime A, Said-Nahal R, Langella P, Chiocchia G, et al. Faecal microbiota study reveals specific dysbiosis in spondyloarthritis. Ann Rheum Dis 2017;76: 1614-22.

9. Eder L, Law T, Chandran V, Shanmugarajah S, Shen H,
Rosen CF, et al. Association between environmental factors and onset of psoriatic arthritis in patients with psoriasis. Arthritis Care Res (Hoboken) 2011;63:1091-7.

10. Pattison E, Harrison BJ, Griffiths CE, Silman AJ, Bruce IN. Environmental risk factors for the development of psoriatic arthritis: results from a case-control study. Ann Rheum Dis 2008;67:672-6.

11. Ward MM, Reveille JD, Learch TJ, Davis JC Jr, Weisman $\mathrm{MH}$. Occupational physical activities and long-term functional and radiographic outcomes in patients with ankylosing spondylitis. Arthritis Rheum 2008;59:822-32.

12. Hsieh J, Kadavath S, Efthimiou P. Can traumatic injury trigger psoriatic arthritis? A review of the literature. Clin Rheumatol 2014;33:601-8.

13. Rudwaleit M, van der Heijde D, Landewé R, Akkoc N, Brandt J, Chou CT, et al. The Assessment of SpondyloArthritis International Society classification criteria for peripheral spondyloarthritis and for spondyloarthritis in general. Ann Rheum Dis 2011;70:25-31.

14. Lambert RG, Bakker PA, van der Heijde D, Weber U, Rudwaleit M, Hermann KG, et al. Defining active sacroiliitis on MRI for classification of axial spondyloarthritis: update by the ASAS MRI working group. Ann Rheum Dis 2016; 75:1958-63.

15. Creemers MC, Franssen MJ, van't Hof MA, Gribnau FW, van de Putte LB, van Riel PL. Assessment of outcome in ankylosing spondylitis: an extended radiographic scoring system. Ann Rheum Dis 2005;64:127-9.

16. van der Linden S, Valkenburg HA, Cats A. Evaluation of diagnostic criteria for ankylosing spondylitis. A proposal for modification of the New York criteria. Arthritis Rheum 1984;27:361-8.

17. Tinazzi I, McGonagle D, Aydin SZ, Chessa D, Marchetta A, Macchioni P. 'Deep Koebner' phenomenon of the flexor tendon-associated accessory pulleys as a novel factor in tenosynovitis and dactylitis in psoriatic arthritis. Ann Rheum Dis 2018;77:922-5.

18. Blachier M, Canouï-Poitrine F, Dougados M, Lethuaut A, Fautrel B, Ferkal S, et al. Factors associated with radiographic lesions in early axial spondyloarthritis. Results from the DESIR cohort. Rheumatology (Oxford) 2013;52: 1686-93.

19. Poddubnyy D, Haibel H, Listing J, Märker-Hermann E, Zeidler H, Braun J, et al. Cigarette smoking has a dose-dependent impact on progression of structural damage in the spine in patients with axial spondyloarthritis: results from the GErman SPondyloarthritis Inception Cohort (GESPIC). Ann Rheum Dis 2013;72:1430-2.

20. Jeong H, Yoon JY, Park EJ, Hwang J, Kim H, Ahn JK, et al. Clinical characteristics of nonradiographic axial spondyloarthritis in Korea: a comparison with ankylosing spondylitis. Int J Rheum Dis 2015;18:661-8.

21. Glintborg B, Sørensen IJ, Østergaard M, Dreyer L, Mohamoud AA, Krogh NS, et al. Ankylosing spondylitis versus nonradiographic axial spondyloarthritis: comparison of tumor necrosis factor inhibitor effectiveness and effect of HLA-B27 status. An Observational Cohort Study from the Nationwide DANBIO Registry. J Rheumatol 2017;44:59-69.

22. Schett G, Lories RJ, D'Agostino MA, Elewaut D, Kirkham B, Soriano ER, et al. Enthesitis: from pathophysiology to treatment. Nat Rev Rheumatol 2017;13:731-41. 